\title{
Sedation for Bronchoscopy and Complications in Obese Patients
}

\author{
Irtaza Khan ${ }^{a}$ Arjun B. Chatterjee ${ }^{b}$ Christina R. Bellinger ${ }^{b}$ Edward Haponik ${ }^{b}$

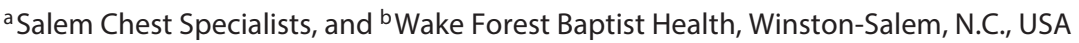

\section{Key Words}

Bronchoscopy · Sedation · Obesity · Complications

\begin{abstract}
Background: Bronchoscopy is a safe and minimally invasive diagnostic tool, but no studies have reported prospectively on sedation and outcomes in patients with objectively defined obesity. Objectives: The purpose of the study is to determine if obese patients require more sedation or had more procedural complications during bronchoscopy under moderate sedation than non-obese patients. Methods: We evaluated complications and sedation requirements in non-obese versus obese patients, defined by multiple criteria including body mass index (BMI), neck circumference, abdominal height, and Mallampati scores. Results: Data were collected prospectively in 258 patients undergoing bronchoscopy under moderate sedation. By varying criteria, there were the following proportions of obese patients: $30 \%$ by BMI $>30$, $39 \%$ by neck circumference $>40 \mathrm{~cm}$, and $35 \%$ by abdominal height $>22 \mathrm{~cm}$ in males and $>20 \mathrm{~cm}$ in females. Sedative and analgesic dosing was not clinically significantly higher in obese patients than in non-obese patients. There was no difference in complications or procedural success based on obesity criteria. Hemoglobin oxygen desaturations occurred more often during bronchoscopy in patients with increasing
\end{abstract}

Mallampati scores $(p=0.04)$, but this had no effect on bronchoscopy time or successful completion of the procedure. A subset of patients with previous polysomnogram-proven obstructive sleep apnea were more likely to have earlier termination of their procedure (15.8\%) than patients with no diagnosed sleep apnea ( $2.3 \% ; p=0.002)$. Conclusion: $\ln$ this prospective assessment of patients with obesity, we found neither clinically significant differences in sedation needs nor increases in complications in obese versus non-obese patients using a variety of indices of obesity.

(C) 2016 S. Karger AG, Basel

\section{Introduction}

Obesity is a growing problem worldwide. According to the World Health Organization, nearly 600 million adults worldwide were obese in 2014. Alarmingly, the obesity prevalence more than doubled from 1980 to 2014 [1]. Obesity rates in the USA doubled from 14.5 to $30.9 \%$ [2] from 1971 to 2000 , increasing to $32.2 \%$ in males and $35.5 \%$ in females in 2008 [3, 4]. Bronchoscopy, though known to be generally a safe procedure, has potential complications ranging from nausea, vomiting, and headache to cardiorespiratory failure and death [5]. A review of older data demonstrated severe complications to in-

\section{KARGER}

E-Mail karger@karger.com

www.karger.com/res
C 2016 S. Karger AG, Basel

0025-7931/16/0923-0158\$39.50/0
Christina R. Bellinger

Department of Pulmonary/Critical Care, Wake Forest Baptist Health Medical Center Blvd

Winston-Salem, NC 27157 (USA)

E-Mail cbelling@wakehealth.edu 
clude cardiac arrest $(0.02 \%)$, bronchospasm $(0.03 \%)$, and death $(0.02 \%)$ [6]. This has remained unchanged over the decades, as displayed by data on a large cohort of over 23,000 patients showing a total severe complication rate of $0.637 \%$, including cardiac arrhythmias (0.001\%), bronchospasm $(0.003 \%)$, tracheal perforation $(<0.001 \%)$, pneumothorax $(<0.001 \%)$, and massive hemoptysis $(0.002 \%)$ as well as a mortality rate of $0.013 \%$ [5].

Although obesity is highly prevalent, the risks of bronchoscopy in this patient population have not been defined. As with many interventions including sedation or anesthesia, the risk of complications from bronchoscopy is often presumed to be more common in obese patients due to the large volume of distribution of drugs and potentially difficult airways. Remarkably, we found no prospective evaluation of bronchoscopy in obese patients. The aim of our investigation was to assess whether there are differences in the amount of sedation required for bronchoscopy or the frequency of complications in obese patients as compared to non-obese patients.

\section{Methods}

After the study had been approved by our institutional review board, we prospectively followed all patients 18 years or older undergoing flexible bronchoscopy under moderate sedation at the endoscopy suite of our institution from January 2010 to January 2011. Bronchoscopies performed outside the endoscopy suite (e.g. in the intensive care units) or those performed under general anesthesia were excluded from the study. All bronchoscopies were performed using the Olympus 160/180 flexible bronchoscope, with the exception of endobronchial ultrasound, where the Olympus ${ }^{\circledR}$ BF-Convex Scope XBF-UC160 F-OL8 with a 22-gauge needle was used. Sedative and analgesia dosing was at the discretion of the bronchoscopist. Bronchoscopy was performed by skilled bronchoscopists usually with the assistance of a trainee.

Our primary outcome was the amount of sedation required in obese patients undergoing bronchoscopy as compared to the nonobese population. Our secondary outcome measures included the time required for the procedure and recovery, the decrease in hemoglobin oxygen saturation and subsequent increase in supplemental oxygen administration, the difference in the types of procedures performed and complications between the groups, and the overall success of the procedure (defined prospectively as achievement of the goals of bronchoscopy).

As the standard of care, the patients were observed for complications in our recovery suite until deemed stable by the nursing staff for discharge. They were assessed by a physician study team member for further complications in person (if it concerned an inpatient) within $24 \mathrm{~h}$ or by telephone at the time of communication of the results of the bronchoscopy.

Multiple criteria were used to define obesity and were recorded by the investigators prior to bronchoscopy. The criteria included: 1 a body mass index (BMI) of $>30$ [7];

Sedation for Bronchoscopy and

Complications in Obese Patients
2 a neck circumference of $>40 \mathrm{~cm}$ [8-10];

3 an abdominal height of $>22 \mathrm{~cm}$ in $\mathrm{men}$ and $>20 \mathrm{~cm}$ in women [11];

4 Mallampati scores [12].

Neck circumference was measured at the level of the cricoid cartilage with the patient looking straight ahead. Abdominal height was measured with the patient lying supine, from the highest abdominal point vertically down to the top of the bronchoscopy table. Mallampati scores were assigned on a scale of 1-4 by the evaluating physician team member according to the extent of visibility of the posterior oropharynx.

\section{Analysis}

Demographic data were compared for intergroup differences using Student's t test. Continuous outcome variables were regressed using a generalized linear model with a normal distribution. In the event the regression was significant, we calculated the maximum difference between extremes in the data to search for clinically meaningful differences. In cases where statistical significance was reached, we also categorized the data and used Student's t test or Fisher's exact test, as appropriate, to compare categories. Our initial power analysis was unfounded, since we were unable to use published data to estimate outcome frequencies. In the interim analysis, we used initial frequencies of outcomes of midazolam and fentanyl doses to perform a power calculation. An $\alpha$ of 0.05 was used for analytical purposes.

\section{Results}

A total of 258 patients were included in the study. Using the different criteria to define obesity, the distribution of patients was as follows: according to BMI $(n=258), 180$ non-obese, 78 (30.2\%) obese; according to neck circumference ( $\mathrm{n}=249), 152$ non-obese, $97(38.9 \%)$ obese; according to abdominal height ( $\mathrm{n}=245), 159$ non-obese, 86 (35.1\%) obese (fig. 1). Nineteen patients (7\%) had previously diagnosed obstructive sleep apnea (OSA).

Age, gender, and bronchoscopy characteristics are detailed in table 1 . When assessed by BMI, the mean dose of fentanyl was $43 \mu \mathrm{g}$ in the non-obese and $51 \mu \mathrm{g}$ in the obese group ( $\mathrm{p}<0.03)$. There was no significant difference in the dose of midazolam required between the non-obese and the obese population (1.9 and $2.2 \mathrm{mg}$, respectively; $\mathrm{p}=0.09$ ). The mean dose of fentanyl when assessed by neck circumference was $44 \mu \mathrm{g}$ in the non-obese and $50 \mu \mathrm{g}$ in the obese group, respectively $(\mathrm{p}=0.08)$. Similarly, when abdominal height was compared, the mean fentan$\mathrm{yl}$ dose administered was 44 and $50 \mu \mathrm{g}(\mathrm{p}=0.15)$ in the non-obese and obese subjects, respectively. The amount of midazolam required, hemoglobin oxygen saturations in the supine and upright seated positions, incremental increases in supplemental oxygen administered during the procedure, and bronchoscopy and recovery times 
Table 1. Relationship of BMI, neck circumference, and abdominal height to bronchoscopy outcomes

\begin{tabular}{|c|c|c|c|c|c|c|c|c|c|}
\hline & \multicolumn{3}{|l|}{ BMI } & \multicolumn{3}{|c|}{ Neck circumference } & \multicolumn{3}{|c|}{ Abdominal height } \\
\hline & non-obese & obese & $\mathrm{p}$ & non-obese & obese & $\mathrm{p}$ & non-obese & obese & $\mathrm{p}$ \\
\hline Mean age, years $(n)$ & $60.9(180)$ & $58.5(77)$ & 0.16 & $59.7(152)$ & $61.2(97)$ & 0.39 & $61.2(159)$ & $58.5(86)$ & 0.13 \\
\hline Mean fentanyl, $\mu g(n)$ & $43(170)$ & $51(73)$ & $0.03 *$ & $44(143)$ & $50(91)$ & 0.08 & $44(148)$ & $50(82)$ & 0.15 \\
\hline Mean midazolam, mg (n) & $1.9(179)$ & $2.2(78)$ & 0.09 & $2.0(151)$ & $2.1(97)$ & 0.38 & $2.0(158)$ & $2.2(86)$ & 0.29 \\
\hline Mean oxygen saturations supine, \% (n) & $96.4(178)$ & $95.5(78)$ & 0.30 & $96(150)$ & $96.3(97)$ & 0.7 & $96.5(157)$ & $95.4(86)$ & 0.19 \\
\hline Mean bronchoscopy time, $\min (\mathrm{n})$ & $19.86(173)$ & $19.84(76)$ & 0.99 & $19(146)$ & $21(94)$ & 0.27 & $19.66(152)$ & $20.4(84)$ & 0.68 \\
\hline Mean recovery time from bronchoscopy, $\min (\mathrm{n})$ & $75(72)$ & $80(76)$ & 0.30 & $76(145)$ & $80(94)$ & 0.49 & $78.3(151)$ & $76.6(84)$ & 0.74 \\
\hline
\end{tabular}

$* \mathrm{p}<0.05$.

Fig. 1. Patients prospectively enrolled and their classification as obese or non-obese according to defined parameters.

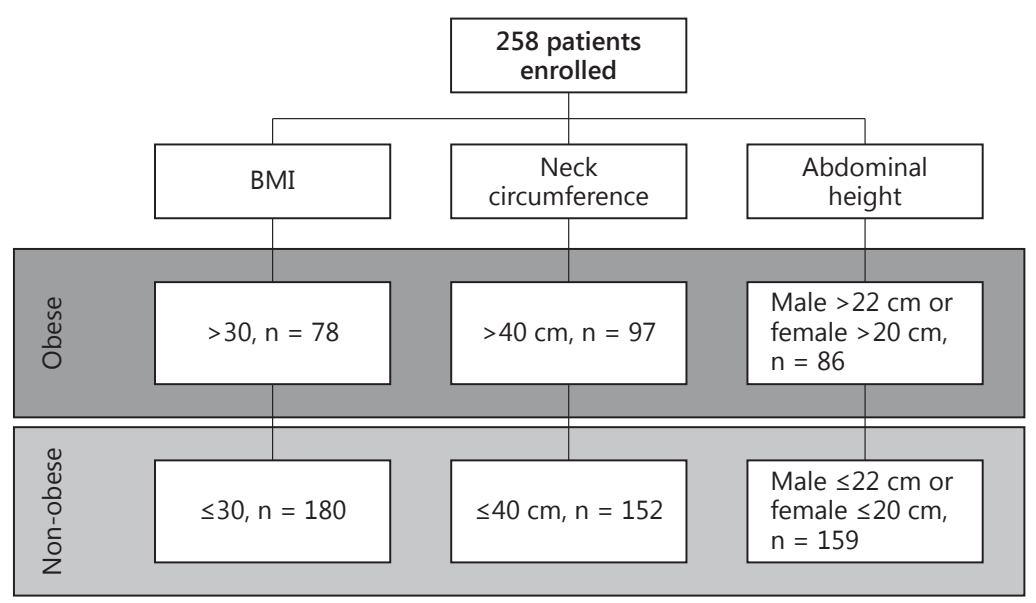

were similar when BMI, neck circumference, and abdominal height were assessed (table 1).

According to the clinical indications and goals, procedures performed during bronchoscopy included bronchoalveolar lavage, bronchial brushings, transbronchial needle biopsy (with and without endobronchial ultrasound), endobronchial fine needle aspiration, endobronchial biopsies, and transbronchial lung biopsies. The types of procedure performed in all the groups were similar, as can be seen in online supplementary table 1 (see www.karger.com/doi/10.1159/000448250 for all online suppl. material). Achievement of the goals of bronchoscopy was similar between patients with differing BMI, neck circumferences, and abdominal heights (table 2).

No difference in complication rates was seen in relation to BMI, neck circumference, or abdominal height (table 2). The most common complication observed during bronchoscopy was hemoglobin oxygen desaturation
(47.3\%) amongst all three of the comparison groups. Other complications included bronchospasm (13\%), cough (6.6\%), hemoptysis (5.8\%), admission to a higher level of care (5\%), bleeding during bronchoscopy $(2.3 \%)$, and respiratory failure $(2.3 \%)$. Two patients $(0.8 \%)$ each had pneumothoraces (not requiring intervention). Transient hypotension occurred in 2 patients $(0.8 \%)$. There was 1 case each of aspiration, pneumonia, and allergic reaction to medications. There were no deaths. Twelve patients (5\%) were admitted to a level of care higher than what they came from, which was to the regular inpatient unit for observation (4 outpatients for oxygen desaturation and 1 patient for bleeding), the step-down unit (1 patient for oxygen desaturation), and the intensive care unit (5 patients for respiratory failure requiring transient noninvasive positive pressure ventilation and 1 patient for mechanical ventilation). 
Table 2. Percentages of complications according to various indices of obesity

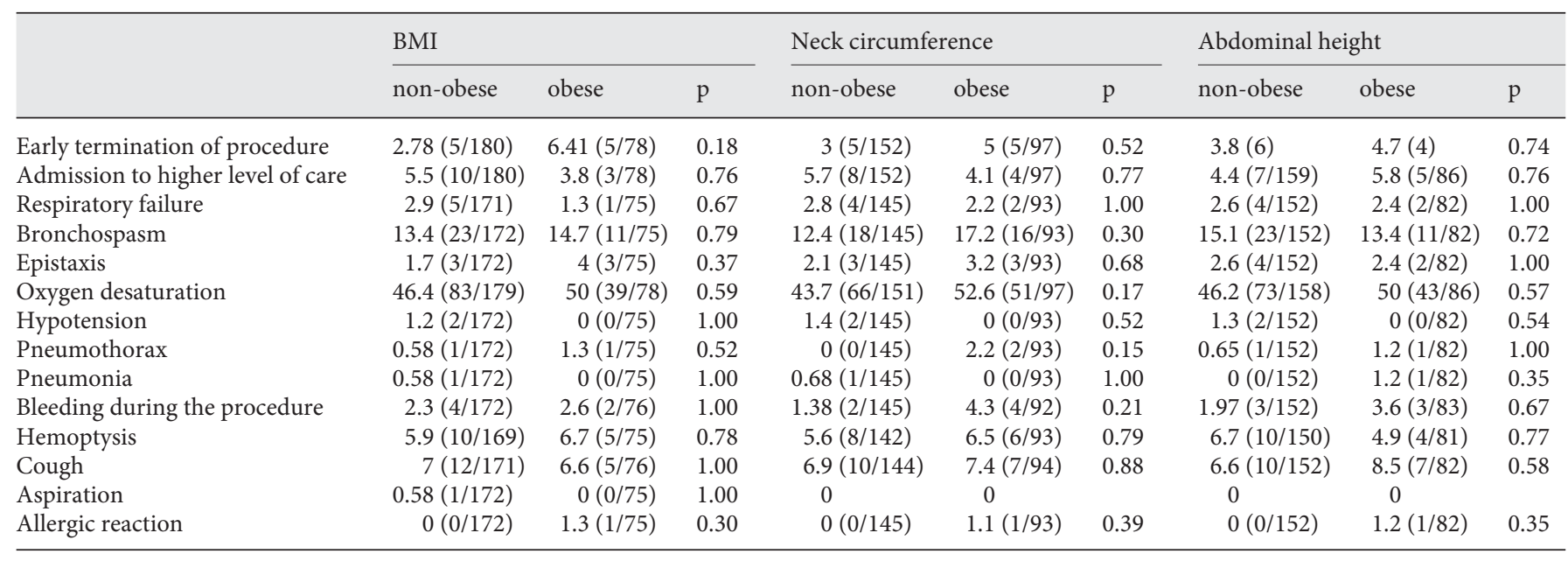

Values are expressed as \% (n/total n). There were no deaths, hallucinations, or arrhythmias.

Table 3. Mallampati score and bronchoscopy characteristics

\begin{tabular}{lccccc}
\hline & \multicolumn{2}{c}{ Mallampati score } & $\mathrm{p}$ \\
\cline { 2 - 5 } & $1(\mathrm{n}=60)$ & $2(\mathrm{n}=72)$ & $3(\mathrm{n}=65)$ & $4(\mathrm{n}=50)$ & \\
\hline Mean age, years & 60.4 & 57.7 & 59.9 & 64.3 & 0.08 \\
Fentanyl, $\mu \mathrm{g}$ & 50 & 47 & 42 & 44 & 0.57 \\
Midazolam, mg & 2.4 & 1.9 & 1.7 & 1.9 & 0.07 \\
$\begin{array}{l}\text { Bronchoscopy time, min } \\
\text { Recovery time from }\end{array} \quad 20$ & 19 & 22 & 19 & 0.79 \\
$\quad$ bronchoscopy, min & 81 & 76 & 73 & 82 & 0.62 \\
\hline
\end{tabular}

When the outcomes of bronchoscopy were compared by the Mallampati score, there was no difference in the amounts of fentanyl and midazolam required between the four Mallampati groups (table 3). Similarly, the bronchoscopy and recovery times were not different. No difference in saturation was seen when the patients were laid supine for bronchoscopy. The procedures performed across the spectrum of Mallampati scores were similar (online supplementary table 2). While the risk of most of the complications was similar across the four Mallampati scores (table 4$)$, a significant $(\mathrm{p}=0.01)$ increase in the rate of oxygen desaturations during bronchoscopy was seen with an increase in Mallampati score (fig. 2), but this did not impact the outcomes of bronchoscopy with regard to either patient disposition or procedural success.

Nineteen patients (7\%) had polysomnogram-proven OSA (mean BMI $40 \pm 10$, range 19-60) diagnosed prior to bronchoscopy. The Mallampati score in those with OSA was 1 in $29 \%(\mathrm{n}=5), 2$ in $12 \%(\mathrm{n}=2), 3$ in $12 \%(\mathrm{n}=$
$2)$, and 4 in $47 \%(\mathrm{n}=8)$, with 2 patients missing scores. Patients with OSA had no higher incidence of transient desaturation ( 37 vs. $20 \%$; $p=0.076$ ), but they did have more early termination of bronchoscopy than patients without known sleep apnea ( 15 vs. $3 \%$; $p=0.002$ ) (fig. 3 ). All three procedures terminated early in patients with sleep apnea were due to hypoxemia. One patient with OSA was transferred to a higher level of care (inpatient floor bed) for observation due to bleeding.

\section{Discussion}

Flexible bronchoscopy has been performed with and without sedation over the decades with improvement in patient tolerance seen with the use of sedation $[13,14]$. A recent review of the literature on the need for sedation in flexible bronchoscopy concluded that use of sedation improves bronchoscopy outcomes and patient tolerance, 
Fig. 2. Percentage of patients undergoing bronchoscopy who experienced transient desaturations. Obese and non-obese patients were segregated based on defined parameters of obesity (BMI, neck circumference, and abdominal height). In the last columns, a higher Mallampati score correlated with a rise in hemoglobin oxygen desaturation.

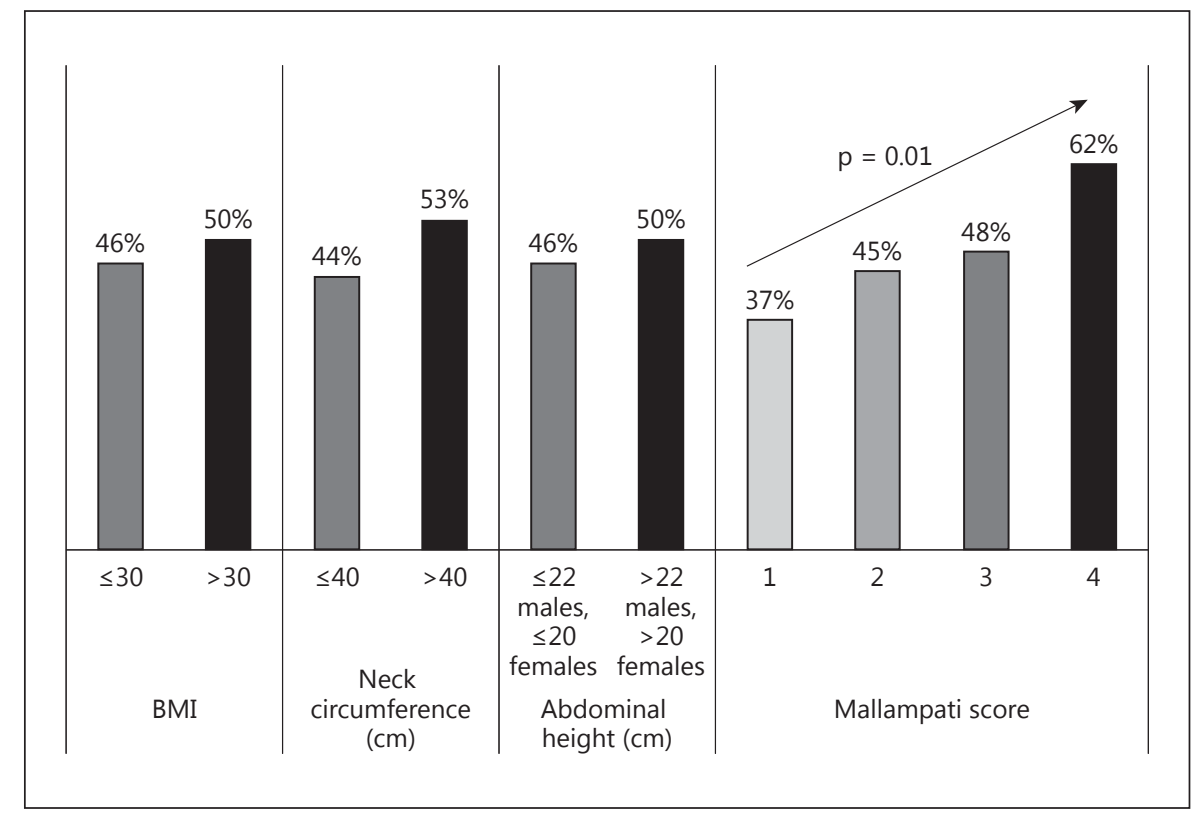

Table 4. Percentage of complications according to Mallampati score

\begin{tabular}{|c|c|c|c|c|c|}
\hline & \multicolumn{4}{|c|}{ Mallampati score } & \multirow[t]{2}{*}{$\mathrm{p}$} \\
\hline & 1 & 2 & 3 & 4 & \\
\hline Admission to higher level of care & $1.7(1 / 60)$ & $9.7(7 / 72)$ & $6.1(4 / 65)$ & $0(0 / 50)$ & 0.09 \\
\hline Respiratory failure & $1.75(1 / 57)$ & $2.9(2 / 67)$ & $3.1(2 / 64)$ & $0(0 / 47)$ & 0.79 \\
\hline Bronchospasm & $15.8(9 / 57)$ & $7.5(5 / 67)$ & $10.8(7 / 65)$ & $25.5(12 / 47)$ & 0.07 \\
\hline Oxygen desaturation & $36.6(22 / 60)$ & $45(32 / 71)$ & $47.7(31 / 65)$ & $62(31 / 50)$ & $0.01^{*}$ \\
\hline Hypotension & $0(0 / 57)$ & $1.5(1 / 67)$ & $0(0 / 65)$ & $0(0 / 47)$ & 0.63 \\
\hline Pneumothorax & $0(0 / 57)$ & $1.5(1 / 67)$ & $1.5(1 / 65)$ & $0(0 / 47)$ & 0.81 \\
\hline Pneumonia & $1.8(1 / 57)$ & $0(0 / 67)$ & $0(0 / 65)$ & $0(0 / 47)$ & 0.53 \\
\hline Bleeding during the procedure & $1.8(1 / 57)$ & $2.9(2 / 68)$ & $1.5(1 / 65)$ & $4.3(2 / 47)$ & 0.89 \\
\hline Hemoptysis & $7(4 / 56)$ & $3(2 / 66)$ & $3.1(2 / 64)$ & $14.9(7 / 47)$ & 0.08 \\
\hline
\end{tabular}

Values are expressed as $\%(\mathrm{n} /$ total $\mathrm{n}) .{ }^{*} \mathrm{p}<0.05$

but cautioned to individualize its judicious use to patients' needs, starting with low doses of sedation [15]. The amount of sedation required depends on the volume of distribution of the given drug as determined by body composition, protein binding, and blood flow [16]. With increase in the percentage of body fat, obese people have an increased volume of distribution of drugs, presumably requiring higher doses of medications. For benzodiaze- pines, this may be true considering their lipophilic properties, resulting in dosage calculations based on total body weight [17]. This relationship may not hold true for fentanyl, especially with the emergence of dosing on the basis of pharmacokinetic mass [18] rather than total body weight, potentially resulting in overestimation of fentanyl dosage in obese patients. Higher doses of sedative medications during flexible bronchoscopy raise concerns over 


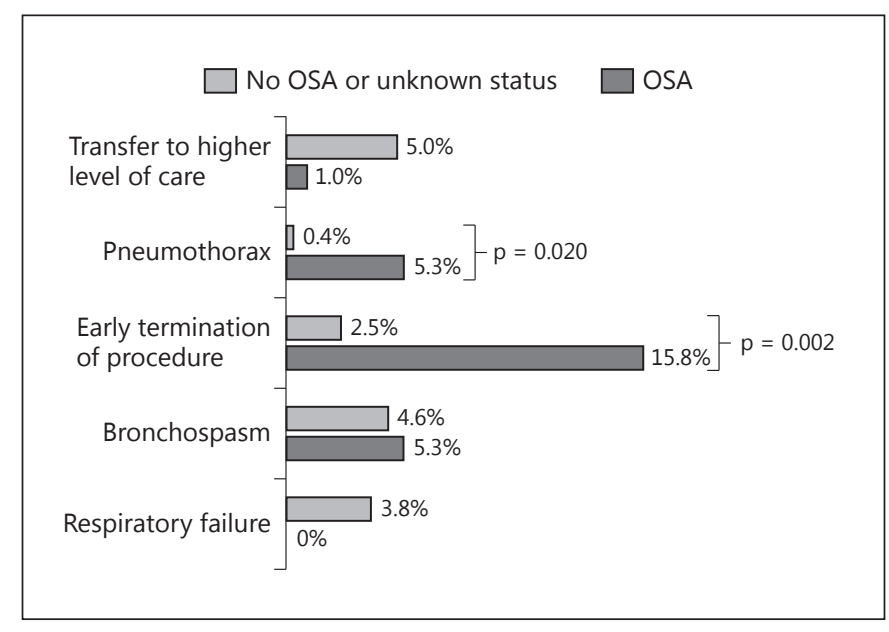

Fig. 3. A subset of patients with OSA were more likely to experience early termination of their procedure compared to patients without known sleep apnea.

potentially higher rates of complications. Alternatively, bronchoscopists might purposely limit sedation because of perceived increased risks in this population. With the rising proportion of obese patients encountered in pulmonary practices, these issues have become increasingly important for bronchoscopists, not only for the purpose of informed consent but also for anticipation of, preparations for, and prevention of adverse events.

Depending upon the criterion used, 30-39\% of our patients were obese, which is consistent with national observations of obesity prevalence. Our observations show that while BMI is not related to dose requirements of midazolam for bronchoscopy, a statistically significant difference exists in the dose of fentanyl given to obese patients; however, the mean difference of $8 \mu \mathrm{g}$ of fentanyl observed between non-obese and obese patients is not clinically significant. The BMI, though traditionally used to define obesity, has its limitations. With high specificity but poor sensitivity [19], the BMI, while accounting for weight and height, fails to assess the body fat percentage. This is especially important in people with a high lean body mass, such as athletes, as the BMI erroneously categorizes them into the obese category. Furthermore, aging-related loss of height may also affect BMI calculations. Accordingly, we addressed multiple measures of obesity in this prospective study.

Obesity correlates with neck circumference and abdominal height larger than what is found in the nonobese population, especially in patients with central adiposity. The latter measures can be used as alternative markers of obesity with implications for potential complications. Abdominal height, independently of BMI, has been found to be a strong predictor of coronary disease [20], pulmonary functional deterioration [21], and mortality [22]. Even considering abdominal height, neck circumference, or the Mallampati score, the dosage requirements for both midazolam and fentanyl did not differ between the groups assessed in our study. The lack of a difference in sedation requirement did not appear to reflect bronchoscopists' hesitance to give medications to the obese patients. This impression is supported by good patient tolerance of a spectrum of diagnostic procedures, generally achieving the goals of bronchoscopy in all groups. The types of bronchoscopic intervention performed, duration of bronchoscopy, and postoperative recovery were similar in all the groups. The relatively low numbers of endobronchial ultrasound-guided bronchoscopies reported reflect their usual performance under general anesthesia at our institution.

In general, indices of obesity were not associated with the duration of the procedure, its premature discontinuation, failure to achieve the diagnostic objectives, or requirements for more intensive postprocedural care. An exception to this was noted in patients with previously diagnosed OSA, in whom early termination of bronchoscopy was more frequent. Further studies are needed to explore the periprocedural risks for patients with OSA undergoing flexible bronchoscopy. The reason for early discontinuation of the procedure was hypoxemia in all cases. This finding, together with the trend toward transient hemoglobin oxygen desaturation, is consistent with the relationship of desaturation to Mallampati score. Cillo and Finn [23] found no oxygen desaturations in patients with Mallampati scores of 3 undergoing uvuloplasty under conscious sedation. Although prior case reports have addressed the roles of the oral/nasal airways and positive pressure ventilation in facilitating bronchoscopy in OSA patients, more information is needed on this subset of obese patients to better assess the unique risks of bronchoscopy. Remarkably, we found no previous series reporting on bronchoscopy in patients with OSA.

A total of 12 (4.4\%) major and 190 (73.6\%) minor complications were seen in our patients. Importantly, events with a major clinical impact - including escalations in the level of care, respiratory failure, and failure to achieve the goals of bronchoscopy - were uncommon and similar to those reported in the literature $(0.3-6 \%)[6$, 24-29]. We believe that the high frequency of minor complications in our patients reflects the prospective nature of our recording and rigorous inclusion of even minor 
events as complications. Hemoglobin oxygen desaturation was the most common minor complication observed, followed by cough lasting less than $24 \mathrm{~h}$. Desaturation with endoscopic procedures is well known, ranging from 30.1 to $47 \%$ [29-31]. As such, it is common practice at our institution to place all patients on oxygen before performing bronchoscopy. Almost half of our patients experienced oxygen desaturation to a degree sufficient to require an increase in supplemental oxygen during the procedure, and this occurred in obese as well as non-obese patients. The frequency of oxygen desaturation was higher among patients with a higher Mallampati score. The decision to increase supplemental oxygen was based on our nurses' assessment of desaturation from baseline, not necessarily on whether a value of less than $90 \%$ was reached. The fact that we included transient desaturation requiring an increase in supplemental oxygen as a minor complication even though the patient returned to baseline within $2 \mathrm{~h}$ of the procedure explains our high rate of minor complications. The latter also reflects the prospective nature of our study and rigorous inclusion of even minor self-limited events. Excluding transient intraprocedural desaturation would reduce our rate of minor complications to $28 \%$.

Patient positioning is expected to have an effect on hemoglobin oxygen saturation, with a recent study showing lower oxygen saturations in both the supine and the upright position in patients with high BMI [32]. Contrary to popular belief, we found no consistent difference in supine oxygen saturations between any of the groups studied. While no postural difference in hemoglobin oxygen saturations related to BMI, neck circumference, or abdominal height was seen, a significant difference was seen with the Mallampati score. This discrepancy suggests that airway dimensions (and potential obstruction by the bronchoscope) represented a clinically more important factor. Factors predicting desaturation with endoscopic procedures include a baseline oxygen saturation below 95\%, an American Society of Anesthesiologist score of 3 or 4, sedation [33], respiratory disease with increasing desaturation seen with decreasing $\mathrm{FEV}_{1}[34,35]$, old age, and anemia [36]. While we found no reports relating obesity to outcomes of bronchoscopy, a BMI $>28$ has been shown to be an independent risk factor for desaturation during gastrointestinal endoscopy [37]. Iwao et al. [38] in 1994 did not find BMI or total endoscopy time to be associated with oxygen desaturation, though it has to be considered that the patients in their study were not sedated.

Several limitations to our study must be considered. Since, to the best of our knowledge, this is the first inves- tigation into the effects of obesity on the amount of sedation required for bronchoscopy, we did not have the means of calculating the required number of patients to be enrolled to assess for a significant difference. It may be that within a larger cohort we would have detected greater differences in the various patient characteristics. Adjustments to the dosing of sedation were based upon our bronchoscopists' impression of patient tolerance of the procedure rather than a rigid protocol. The decision to increase the supplemental oxygen provided to the patients, and hence the assessment of hypoxia, was based on our nurses' evaluation. Although a consistent nursing team assisted in bronchoscopy, this exposed the interpretation of presumed versus true hypoxia to variation. We did not employ a caliper to measure abdominal height. Even though abdominal height was measured by one of the three study team members collecting the data, this may potentially have resulted in nonstandardized measurements of this parameter. Other potential concerns are related to the well-recognized respiratory complications of obesity. Because none of the patients required arterial blood gas measurements or capnography, we could not assess the effects of obesity hypoventilation. Only 7\% of our cohort had diagnosed sleep apnea; the remaining $91 \%$ did not have any results to prove or refute the presence of sleep apnea.

\section{Conclusion}

When obesity was characterized prospectively by multiple criteria (BMI, neck circumference, abdominal height, and Mallampati score), there was no difference in the dose of midazolam required for sedation. Patients defined as being obese by the criterion of BMI were found to require higher doses of fentanyl, but the difference was not clinically significant. No differences in procedural characteristics and outcomes as well as intra- and postprocedural complications were seen between the nonobese and obese groups, except that patients with higher Mallampati scores experienced more oxygen desaturations. Patients with previously diagnosed OSA were noted to more frequently have early termination of bronchoscopy due to hypoxemia, though none of those patients required a higher level of care after the procedure. When performed in a carefully monitored setting and following established guidelines, flexible bronchoscopy using moderate sedation is safe in most obese patients. 


\section{References}

1 World Health Organization: Obesity and overweight. http://www.who.int/mediacentre/ factsheets/fs311/en/ (accessed March 29, 2016).

-2 Flegal KM, Carroll MD, Ogden CL, Johnson CL: Prevalence and trends in obesity among US adults, 1999-2000. JAMA 2002;288:17231727.

3 Flegal KM, Carroll MD, Ogden CL, Curtin LR: Prevalence and trends in obesity among US adults, 1999-2008. JAMA 2010;303:235241.

4 WHO Global Infobase. https://apps.who.int/ infobase/Comparisons.aspx (accessed May 1, 2012).

5 Jin F, Mu D, Chu D, Fu E, Xie Y, Liu T: Severe complications of bronchoscopy. Respiration 2008;76:429-433.

$\checkmark 6$ Suratt PM, Smiddy JF, Gruber B: Deaths and complications associated with fiberoptic bronchoscopy. Chest 1976;69:747-751.

7 World Health Organization: Global Database on Body Mass Index. www.who.int/bmi/ index.jsp?introPage $=$ intro_3.html (accessed May 1, 2012).

8 Chung F, Yegneswaran B, Liao P, Chung SA, Vairavanathan S, Islam S, Khajehdehi A, Shapiro CM: STOP questionnaire: a tool to screen patients for obstructive sleep apnea. Anesthesiology 2008;108:812-821.

$\checkmark 9$ Sweitzer BJ, Smetana GW: Identification and evaluation of the patient with lung disease. Med Clin North Am 2009;93:1017-1030.

10 Katz I, Stradling J, Slutsky AS, Zamel N, Hoffstein V: Do patients with obstructive sleep apnea have thick necks? Am Rev Respir Dis 1990;141(pt 1):1228-1231.

$>11$ Risérus U, de Faire U, Berglund L, Hellénius ML: Sagittal abdominal diameter as a screening tool in clinical research: cutoffs for cardiometabolic risk. J Obes 2010;2010:757939.

$>12$ Mallampati SR, Gatt SP, Gugino LD, Desai SP, Waraksa B, Freiberger D, Liu PL: A clinical sign to predict difficult endotracheal intubation: a prospective study. Can Anaesth Soc J 1985;32:429-434.

13 Maltais F, Laberge F, Laviolette M: A randomized, double-blind, placebo-controlled study of lorazepam as premedication for bronchoscopy. Chest 1996;109:1195-1198.

-14 Putinati S, Ballerin L, Corbetta L, Trevisani L, Potena A: Patient satisfaction with conscious sedation for bronchoscopy. Chest 1999;115: 1437-1440.

15 Khan I, Haponik E, Chatterjee A, Chin RJ, Conforti J: Is sedation necessary for successful completion of flexible bronchoscopy? Clin Pulm Med 2010;17:244-247.
16 Passannante AN, Rock P: Anesthetic management of patients with obesity and sleep apnea. Anesthesiol Clin North America 2005;23: 479-491, vii.

17 Blouin RA, Warren GW: Pharmacokinetic considerations in obesity. J Pharm Sci 1999; 88:1-7

18 Shibutani K, Inchiosa MA, Sawada K, Bairamian M: Accuracy of pharmacokinetic models for predicting plasma fentanyl concentrations in lean and obese surgical patients: derivation of dosing weight ('pharmacokinetic mass'). Anesthesiology 2004;101: 603-613.

19 Romero-Corral A, Somers VK, Sierra-Johnson J, Thomas RJ, Collazo-Clavell ML, Korinek J, et al: Accuracy of body mass index in diagnosing obesity in the adult general population. Int J Obes (Lond) 2008;32:959-966.

20 Iribarren C, Darbinian JA, Lo JC, Fireman $\mathrm{BH}, \mathrm{Go}$ AS: Value of the sagittal abdominal diameter in coronary heart disease risk assessment: cohort study in a large, multiethnic population. Am J Epidemiol 2006;164:11501159.

21 Ochs-Balcom HM, Grant BJ, Muti P, Sempos CT, Freudenheim JL, Trevisan M, et al: Pulmonary function and abdominal adiposity in the general population. Chest 2006;129:853862.

22 Empana JP, Ducimetiere P, Charles MA, Jouven $\mathrm{X}$ : Sagittal abdominal diameter and risk of sudden death in asymptomatic middleaged men: the Paris Prospective Study I. Circulation 2004;110:2781-2785.

23 Cillo JE Jr, Finn R: Hemodynamics and oxygen saturation during intravenous sedation for office-based laser-assisted uvuloplasty. J Oral Maxillofac Surg 2005;63:752-755.

24 Pue CA, Pacht ER: Complications of fiberoptic bronchoscopy at a university hospital. Chest 1995; 107:430-432.

25 Geraci G, Pisello F, Sciumè C, Li Volsi F, Romeo M, Modica G: Complication of flexible fiberoptic bronchoscopy. Literature review (in Italian). Ann Ital Chir 2007;78:183-192.

26 Pereira W Jr, Kovnat DM, Snider GL: A prospective cooperative study of complications following flexible fiberoptic bronchoscopy. Chest 1978;73:813-816.

27 Dreisin RB, Albert RK, Talley PA, Kryger $\mathrm{MH}$, Scoggin $\mathrm{CH}$, Zwillich CW: Flexible fiberoptic bronchoscopy in the teaching hospital. Yield and complications. Chest 1978;74: 144-149.
28 Dang D, Robinson PC, Winnicki S, Jersmann HP: The safety of flexible fibre-optic bronchoscopy and proceduralist-administered sedation: a tertiary referral centre experience. Intern Med J 2012;42:300-305.

29 Kaparianos A, Argyropoulou E, Sampsonas F, Zania A, Efremidis G, Tsiamita M, Spiropoulos K: Indications, results and complications of flexible fiberoptic bronchoscopy: a 5-year experience in a referral population in Greece. Eur Rev Med Pharmacol Sci 2008;12:355363.

30 Chhajed PN, Aboyoun C, Chhajed TP, Malouf MA, Harrison GA, Tamm M, Leuppi JD, Glanville AR: Sedative drug requirements during bronchoscopy are higher in cystic fibrosis after lung transplantation. Transplantation 2005;80:1081-1085.

-31 Eikermann M, Garzon-Serrano J, Kwo J, Grosse-Sundrup M, Schmidt U, Bigatello L: Do patients with obstructive sleep apnea have an increased risk of desaturation during induction of anesthesia for weight loss surgery? Open Resp Med J 2010;4:58-62

32 Meghjee SP, Marshall M, Redfern EJ, McGivern DV: Influence of patient posture on oxygen saturation during fibre-optic bronchoscopy. Respir Med 2001;95:5-8.

33 Chhajed PN, Wallner J, Stolz D, Baty F, Strobel W, Brutsche MH, Tamm M: Sedative drug requirements during flexible bronchoscopy. Respiration 2005;72:617-621.

34 Moore WC, Evans MD, Bleecker ER, Busse WW, Calhoun WJ, Castro M, et al; National Heart, Lung, and Blood Institute's Severe Asthma Research Group: Safety of investigative bronchoscopy in the Severe Asthma Research Program. J Allergy Clin Immunol 2011;128:328-336.e3.

35 Bellinger CR, Khan I, Chatterjee AB, Haponik E: Bronchoscopy safety in patients with chronic obstructive lung disease. J Bronchol Interven Pulm, accepted for publication.

36 Credle WF Jr, Smiddy JF, Elliott RC: Complications of fiberoptic bronchoscopy. Am Rev Respir Dis 1974;109:67-72.

37 Dhariwal A, Plevris JN, Lo NT, et al: Age, anemia, and obesity-associated oxygen desaturation during upper gastrointestinal endoscopy. Gastrointest Endosc 1992;38:684-688.

38 Iwao T, Toyonaga A, Harada H, Harada K, Ban S, Ikegami M, Tanikawa K: Arterial oxygen desaturation during non-sedated diagnostic upper gastrointestinal endoscopy. Gastrointest Endosc 1994;40:227-280. 